\title{
Review
}

\section{The Role of the Autonomic Nervous System in Hypertension}

\author{
John Amerena, and Stevo Julius
}

\begin{abstract}
The role of the autonomic nervous system in the genesis and maintenance of hypertension is becoming clearer with time. Early research suggested that increased vascular resistance in hypertension was not dependent on excess autonomic tone and thus it was presumed that the autonomic nervous system had little to do with hypertension. More recent studies have demonstrated that the initial hemodynamic abnormality in hyperkinetic borderline hypertension is "normal" vascular resistance, with an elevated cardiac optput and heart rate, associated with markers of increased sympathetic and decreased parasympathetic tone of central origin. Over time there is a transition to the high peripheral resistance and normal cardiac output hemodynamic state characteristic of established hypertension, which is due to the development of adaptive structual changes in the peripheral resistance vessels and heart. The autonomic abnormality in hypertension and subsequent vascular and cardiac changes may explain some of association between hypertension and risk factors for coronary heart disease. The autonomic imbalance found in hypertension may not be a chance occurrence and we postulate that it is due to the inheritance of the genes responsible for a more pronounced defense reaction, which in earlier times may have conferred a survival advantage hut now permit the negative impact of this trait to become evident. (Hypertens Res 1995; 18: 99-110)
\end{abstract}

Key Words: autonomic, hypertension, hemodynamics, defense reaction

\begin{abstract}
Although it is often believed that there is a link between human hypertension and the nervous system, the scientific evidence for the role of neurogenic factors in the genesis and maintenance of human hypertension is not extensive. Early this century Geisbock (1) noted that there was an unusual frequency of hypertension in "directors of big enterprises who had demanding jobs and who, due to psychic overload, became nervous". Despite this and other observations, the case for an association between the nervous system and hypertension was not strong due to the work of several investigators who demonstrated that in hypertensive patients particularly, an increase in vascular resistance remained after abolition of local sympathetic tone. Pickering (2) showed that even after blockade of the forearm sympathetics with local anesthesia, vascular resistance remained elevated in hypertensive patients compared with normal controls. Conway (3) and Sivertsson (4) found similar results when they abolished the effects of autonomic tone on the forearm vasculature by producing maximal vasodilation with ischemic exercise. These results were supported by Korner (5), who demonstrated that the total systemic vascular resistance in hypertensive patients remains elevated even after complete cardiovascular autonomic blockade. Since the major hemodynamic abnormality in established hypertension is an eleva-
\end{abstract}

tion of total peripheral resistance (6), and the elevation persisted even in the absence of sympathetic drive, these findings suggested that the autonomic nervous system was not involved in the maintenance of hypertension. Further evidence supporting this line of argument against a major role of excessive sympathetic drive as a primary cause of hypertension also came from studies which consistently found normal levels of plasma catecholamines in established hypertension $(7,8)$.

The lack of involvement of the autonomic nervous system in hypertension suggested by these human studies is supported by the results of experiments in animals. When investigators tried to produce sustained hypertension in animals by using strictly neurogenic methods they were largely unsuccessful, whereas with other methods it was relatively easy. Renal artery stenosis, partial renal ablation and salt loading have all caused predictable, sustained hypertension in rats. Only transient and/or labile elevation in blood pressure has been produced by removal of arterial baroreceptors (9), direct stimulation of the paleocortex (10), stimulation of the Stellate Ganglion (11), exposing rats to noise (12) and operant conditioning of primates (13). It thus appeared to many investigators in the field, including Guyton (14), that the nervous system is capable of regulating blood pressure in the

From the Department of Internal Medicine, Division of Hypertension, University of Michigan, Michigan, USA.

Address for Reprints: John Amerena, MBBS, Department of Internal Medicine, Division of Hypertension, University of Michigan, 3918 Taubman Center, Ann Arbor, Michigan 48109-0356, USA.

Received December 2, 1994. 
short term but that it has little role in the development and maintenance of human hypertension.

Even though these early studies did not suggest a causal relationship between abnormalities in the autonomic nervous system and chronic hypertension in the general population, a body of evidence which did link changes in autonomic function and the evolution of hypertension in some patients was slowly accumulating. Numerous investigators (15-19) observed that in very mild early hypertension the major hemodynamic features are high cardiac output with normal peripheral vascular resistance. As opposed to this, severe established hypertension is usually characterized by normal cardiac output with elevated peripheral resistance. The high cardiac output/normal peripheral resistance of early hypertension is often accompanied by an elevated heart rate so that this hemodynamic profile is often referred to as the "hyperkinetic state" or "hyperkinetic borderline hypertension." The combination of elevated heart rate and cardiac output associated with high oxygen consumption is characteristic of hypermetabolic states such as physical exercise or hyperthyroidism, but the vascular resistance is invariably low in these circumstances so that the blood pressure remains close to normal. In the "hyperkinetic borderline hypertensive" state oxygen consumption has been noted to be elevated (17-20) but the vascular resistance, which should be low given the observed levels of blood pressure, cardiac output, heart rate and oxygen consumption, is nor$m a l$ and is, therefore, inappropriately high (21). This dissociation between total peripheral resistance, cardiac output and oxygen consumption in the hyperkinetic state can theoretically, at least, be attributed to excessive sympathetic tone. Increased central sympathetic outflow to the heart may raise the cardiac output and increase oxygen consumption by stimulation of peripheral metabolic receptors. Simultaneous enhancement of $\alpha$-adrenergic tone may also produce vasoconstriction and counteract the reflex vasodilation which should occur with an increase in cardiac output and oxygen consumption. Thus, in the hyperkinetic state, there is an inappropriately "normal" peripheral resistance rather than the low peripheral resistance which should be present with these hemodynamic conditions under normal physiological circumstances.

Whether this unusual constellation of hemodynamics found in hyperkinetic borderline hypertension was part of a generalized autonomic nervous abnormality was unclear. To determine if there was an underlying neurogenic basis for this state, receptor blockers, which give more information about autonomic function than the more commonly used measures of catecholamine levels and turnover (22), were given to subjects with hyperkinetic borderline hypertension to produce an autonomic blockade. When intravenous propranolol was followed by atropine, the responses symbolized the amount of $\beta$-adrenergic drive to the heart and the degree of cardiac parasympathetic inhibition respectively (23). As depicted in Fig. 1, combined sympathetic and para-sympathetic blockade abolished the difference between hypertensive patients and normotensive controls, showing that the elevated cardiac output in borderline hypertension is indeed neurogenic. Hypersensitivity of $\beta$-receptors has been postulated as a possible cause of the hemodynamic pattern seen in the hyperkinetic state and indeed this has been described in a group of hyperkinetic patients, some of whom also had mild hypertension (24). However, in the patients described in Fig. 1, after $\beta$-adrenergic blockade the cardiac output in hyperkinetics was still significantly higher than in normotensive controls and became normal only after additional parasympathetic blockade with atropine. This implies that both branches of the autonomic innervation of the heart are involved in the elevation of the cardiac output, suggesting that the abnormality is central in origin rather than due to an isolated hypersensitivity of $\beta$-adrenergic receptors. Another important point demonstrated by Fig. 1 , is that after $\beta$-adrenergic blockade, patients with hyperkinetic borderline hypertension had a larger fall in cardiac output and heart rate than control subjects, indicating an elevated sympathetic drive in this group. After atropine the situation is reversed; the borderline hypertensive patients responded with a smaller increase in heart rate and cardiac output reflecting less parasympathetic inhibitory tone. This suggests that in borderline hyperkinetic hypertension there is a reciprocal relationship consisting of higher sympathetic discharge coupled with less parasympathetic activity of central origin as this pattern is typical of the integrative function of the cardiovascular center in the medulla oblongata.

The medulla oblongata receives input from

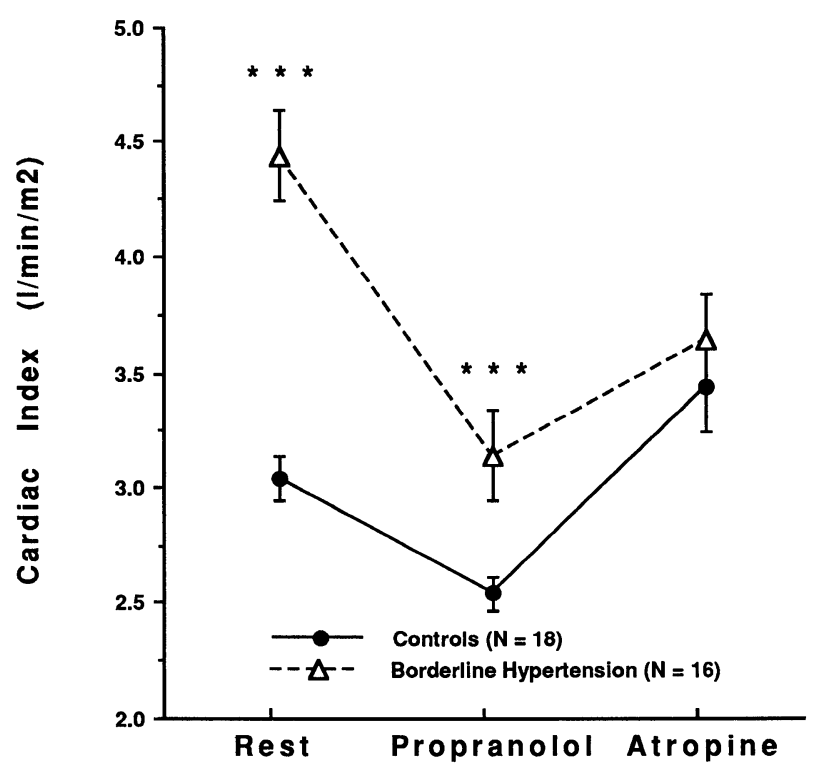

Fig. 1. Influence of the stepwise blockade of the autonomic system on cardiac index. First, propranolol $(0.2$ $\mathrm{mg} / \mathrm{kg} \mathrm{IV}$ ) was given and the measurement taken seven minutes after completion of the injection. Another measurement was taken seven minutes after atropine (0.04 $m g / k g I V)$. Results given as mean \pm SEM. ${ }^{* * *} \mathrm{p}<0.001$. 
numerous sources, all of which can result in reciprocal changes in sympathetic and parasympathetic outflow. Afferent input from arterial baroreceptors characteristically produces this type of reciprocal response and thus decreased baroreceptor sensitivity might be responsible for the hemodynamic constellation found in neurogenic borderline hypertension. This has been found by several authors $(25-28)$ and more recently it has been reported that arterial baroreceptors are less sensitive in children of hypertensive parents (28). We were unable to confirm these observations in our patients (29) perhaps due to differences in the populations studied, and Eckberg (26) has shown that patients with the mildest elevation of blood pressure had normal baroreceptor sensitivity. Thus the role of changes in baroreceptor sensitivity in borderline hyperkinetic hypertension is unclear, as the evidence is somewhat conflicting.

There are several other lines of evidence which suggest that the sympathetic nervous system plays a pivotal role in hyperkinetic borderline hypertension. A number of investigatars have shown (30-34) there is an increased discharge rate in sympathetic fibers in the peroneal nerve of borderline hypertensive patients when measured by microneurography. Spectral analysis of the heart rate in borderline hypertensive patients shows a characteristic pattern of excess sympathetic activity coupled with diminished parasympathetic activity (35), which adds additional weight to the premise of a central origin for the borderline hypertensive state. As well, catecholamine levels have been shown to be elevated in borderline hypertension, $(7,8,36)$ and increased norepinephrine spillover from the heart and kidneys has been reported in young patients with borderline and mild established hypertension (37). These results, taken together with the experimental data described above, suggest that the sympathetic nervous system does play a major role in producing hypertension in some patients.

\section{The Development of Established Hypertension from Early Borderline Hypertension}

It has often been assumed that hyperkinetic borderline hypertension presented little in the way of cardiovascular risk to patients. It is now becoming clearer that this is not the case, as there is mounting evidence supporting the view that patients with a "neurogenic" mechanism for their hypertension are at increased risk.

Several studies have shown that a fast resting heart rate is predictive of future hypertension (38-40) independent of blood pressure elevation. Levy et al.(38) elegantly demonstrated this in a study on the five-year incidence of hypertension in "healthy" U.S. military personnel in a seminal study on predictors of future hypertension. Normotensive subjects with a normal heart rate at screening had a very low incidence of developing hypertension at 5 years. Subjects who had an increased heart rate but normal blood pressure were two to three times as likely to develop hypertension compared to their counterparts with normal heart rates. The incidence of developing hypertension in these fast heart rate normotensive individuals, was about the same as in individuals who had borderline hypertension but normal resting heart rates at screening. When subjects had both tachycardia and borderline hypertension the risk of becoming hypertensive increased markedly.

Several investigators (41-44) looked at the changes in blood pressure and cardiac output over time in borderline hypertensives to further clarify the role of the autonomic nervous system in the evolution of hypertension. Despite the blood pressure remaining in the borderline range in all but one study (42) there was a decrease in cardiac output with time in all patients. These studies were conducted over a relatively short period of time, which may explain why there was a failure to show progression toward sustained hypertension. The importance of time in the development of sustained hypertension became clearer with Lund-Johanssen's work when he investigated the hemodynamics in subjects who had early hypertension, with minimal blood pressure elevation and no target organ damage. When initially studied many of his subjects had a hyperkinetic circulation (17) but after 10 years this had disappeared, despite the blood pressure remaining in the same borderline range as at the outset. The hemodynamic profile had changed even more after 20 years (45) as many subjects had by then developed established hypertension characterized by high peripheral resistance/normal cardiac output and the majority of them were taking antihypertensive medication. Although the LundJohanssen sample was small, his observations combined with Levy's epidemiologic data on tachycardia as a predictor of hypertension suggest that the hyperkinetic state is often a precursor of future hypertension.

Patients with borderline hypertension have a higher risk of developing sustained hypertension relative to the normotensive population, but the excess risk is not great. It has been reported (46) that about $20 \%$ of borderline hypertensives will develop a more advanced form of hypertension over 10 years. Even patients with mild established hypertension do not inevitably progress to more severe forms of hypertension as about one third of patients will show improvement and revert to lower values after 3 years (46). In these two groups of hypertensive patients there is a significant proportion of patients who have a "neurogenic" component to their hypertension. Whether the presence of an underlying neurogenic mechanism carries an increased likelihood of progression to more severe hypertension is not at all clear as all patients in these categories do not invariably develop established hypertension.

Most literature on hyperkinetic borderline hypertension has been derived from studies conducted on subjects who have volunteered to be investigated. When studied in our laboratory in Ann Arbor about a third of the volunteers had a hyperkinetic circulation, but the subjects were mostly young 
male University students. Whether the subjects with hyperkinetic stigmata were a distinct subgroup was not clear until the invasive hemodynamic data collected over a number of years on normotensive and borderline hypertensive subjects were analyzed specifically with this intent. When the individuals were originally studied they were selected by their blood pressure level and not on the basis of their hemodynamic profiles. Since both patients and control subjects were of the same age and sex, the groups were combined for the purpose of analysis and the distribution of heart rate and cardiac output was examined to determine if it was normal or skewed. This initial analysis indicated that for both variables the distribution curve was skewed towards the high values. Multiple models fitted separately for the heart rate and cardiac output were then used to determine if the distribution represented a single population with the mean shifted towards higher values or if two distinct sub-populations existed. A highly significant fit for two populations was found, and based on this, secondary analysis was performed using the co-mingling technique developed by Schork NJ and Schork MA (48). When data were adjusted for age, weight and blood pressure this mixture analysis showed that even when high heart rate and cardiac output were combined, two different populations were still present. Individuals belonging to the high output-heart rate subset were then identified and their original diagnostic blood pressure classification was determined. Only $2 \%$ of the normotensive individuals were hyperkinetic whereas $25 \%$ of the borderline hypertension group belonged to the hyperkinetic subset. This analysis thus confirmed that amongst patients studied in a laboratory setting there is a hyperkinetic subgroup whose hemodynamic characteristics are different from normotensive subjects and from the rest of patients with borderline hypertension.

Whether the frequency of the hyperkinetic state in this sample of subjects is representative of the true prevalence in the general population has only recently been clarified. The existence of two distinct subgroups within the borderline hypertensive population was confirmed in an epidemiological study performed in Tecumseh, Michigan. Hemodynamic data, including noninvasive measurement of cardiac output, were prospectively collected in unselected individuals in a rural community setting. Thirty-seven percent of all subjects with borderline hypertension (as defined by one or more blood pressure reading of $>140 / 90$ ) in this population had characteristics of a hyperkinetic circulation (48). It therefore appears likely that the neurogenic-hyperkinetic type of borderline hypertension not only exists in a laboratory setting but is also present in a substantial number of patients with borderline hypertension in the general population. This makes it unlikely that the hyperkinetic state is merely a byproduct of invasive laboratory procedures or a reflection of selection bias towards particularly anxious people who volunteer to participate in studies conducted in a medical setting. The Tecumseh data demonstrates conclusively that the hyperkinetic state occurs not infrequently in the general population of patients with mild or borderline hypertension, whilst the hemodynamic data obtained in the laboratory suggests that the blood pressure elevation in these individuals is maintained through a neurogenic mechanism (22).

\section{The Hemodynamic Transition from Neurogenic to Non-Neurogenic Hypertension}

Some patients with hyperkinetic borderline hypertension eventually develop established hypertension but the transformation is difficult to understand, superficially at least, given the differences in the hemodynamics between the two conditions. Early hypertension is characterized by elevated cardiac output and "normal" peripheral resistance but the hemodynamic hallmark of established hypertension is a normal cardiac output and an increased peripheral vascular resistance. It has been well documented that in patients with established hypertension regional and systemic vascular resistance remains elevated even after a complete blockade of the autonomic nervous system $(2,5)$. This suggests that vascular tone is not dependent on autonomic tone for its maintenance in established hypertension. Furthermore, if plasma norepinephrine levels are used as an index of sympathetic nervous system activity, it has been found that high plasma catecholamine levels are present in the early phases of hypertension (49-52), but are normal in established hypertension (8). To explain the transformation from hyperkinetic borderline hypertension to established hypertension one must construe a mechanism by which cardiac output decreases and vascular resistance increases in conjunction with the normalization of markers of enhanced sympathetic tone.

Guyton (14) postulated the concept of "total body autoregulation" to explain the hemodynamic transformation from high to normal cardiac output in the evolution of hypertension. This concept proposes that the initiating mechanism is overperfusion of the tissues (flow exceeding metabolic need) which triggers an increase of vascular resistance which then limits flow. There is some doubt, in our minds at least, as to whether this mechanism really is involved in the changing hemodynamic patterns in hypertension. The basic stimulus for autoregulation is overperfusion, where the central nervous system senses that the cardiac output exceeds the oxygen demands of the body. Patients with borderline hypertension associated with high cardiac output have increased oxygen consumption (16-18) so that the increased cardiac output is appropriately matched by higher oxygen consumption. This provides little support for the autoregulatory concept as the mechanism for the hemodynamic transition in the course of the development of hypertension. We believe that it is much more likely that the decrease in cardiac output in the course of hypertension is a direct consequence of the combined effects of elevated blood pressure and enhanced sympathetic tone in patients who initially have an hyperkinetic circulation. 
With sustained elevation of sympathetic tone functional downregulation of cardiac $\beta$-adrenergic receptors may occur. Functional downregulation in response to chronic stimulation is an accepted phenomenon and although there are no studies which have quantified numbers of cardiac $\beta$-receptors in normotensive and hypertensive subjects, several functional studies of the cardiac response to $\beta$ adrenergic stimulation support the hypothesis of decreased $\beta$-receptor function in hypertension. It has been shown by our group (53) and others (54) that in patients with borderline hypertension and normal cardiac output there is a decreased heart rate and cardiac output response to equivalent doses of isoproterenol compared with normotensive control subjects. These patients also had a decrease of stroke volume which was even more evident after functional "denervation" of the heart with $\beta$ adrenergic (propranolol) and parasympathetic blockade (atropine) (53). This diminution in stroke volume is most likely due to a combination of decreased cardiac compliance and inadequate myocardial relaxation which both can contribute to reduced left ventricular filling. It is likely that the decline in response to sympathetic drive and the fall in stroke volume with time is the mechanism by which the transition from high cardiac output borderline hypertension to normal cardiac output established hypertension occurs.

The progressive increase in vascular resistance in the course of development of sustained hypertension can be best explained by invoking the structural reinforcement concept of Folkow (55). He postulates that in response to chronically elevated blood pressure there is adaptive vascular hypertrophy of the resistance vessels with progressive thickening of the smooth muscle of the media. The thicker vessel wall encroaches on the vascular lumen and produces an increase in wall/lumen ratio which results in elevated vascular resistance even when the vessel is maximally dilated. These structural changes in the vessel wall render them hyper-responsive to all vasoconstrictive stimuli, thus potentiating and amplifying the already increased minimal vascular resistance. Vascular structural changes and responses of this type have been documented in hypertension patients by Conway (3) and Siverttson (4) and more recently in our laboratory where forearm vascular responsiveness was extensively examined (56).

Although the secondary effects of enhanced sympathetic drive and elevated blood pressure on the heart and the blood vessels can explain the transition from a high cardiac output to a high total peripheral resistance state, a major question still remains unanswered. The sympathetic tone is elevated in the early hyperkinetic phase of hypertension, but it reverts to normal with time (8). The mechanism for this "resetting" of the sympathetic tone has not been definitively proven but our group recently proposed a comprehensive conceptual framework to explain this transition (57). This concept, which is supported by large amounts of crosssectional observations, suggests that the central nervous system exhibits a "blood pressure seeking be- havior". We postulate that in regulating the circulation, the central nervous system tightly governs the blood pressure by permitting large variations in flow and peripheral resistance. In order to achieve such a close regulation of the pressure, the central nervous system must sense both the prevailing and achieved blood pressure. If this is indeed the case, and the central nervous system controls the circulation by regulating and sensing the blood pressure, the disappearance of the enhanced sympathetic tone in the course of hypertension becomes more easily understood. In this setting, the central nervous system is the initiator of elevated blood pressure, and is capable of sensing the blood pressure which is achieved. As structural reinforcement takes place, blood vessels become hyper-responsive so that less sympathetic drive is needed to maintain the same blood pressure elevation. Within this context, the resetting of the sympathetic tone towards normal is an expected physiologic outcome. This concept provides a logical explanation for a chain of events known to occur over time in some patients with hypertension and is worthy of further investigation, although we freely admit its speculative nature and by no means consider it proven.

\section{The Relationship between the Autonomic Nervous System and Coronary Risk Factors in Hypertension}

There is a substantial body of work documenting the association of multiple risk factors for coronary heart disease and established hypertension (58-60). Recent evidence from the Tecumseh study shows that even the mildest forms of blood pressure elevation, so-called "borderline" (49) and "white coat" (61) hypertension, are associated with multiple blood pressure-independent risk factors. We know that sympathetic overactivity, hypertension and coronary risk factors are closely interrelated early in the course of hypertension which raises the intriguing question of whether the excessive sympathetic tone is the underlying mechanism responsible for both the elevation of the blood pressure and for the genesis of the observed risk factors. We will argue that this may well be the case and in doing so will postulate a reason, and a possible physiologic purpose, for excessive sympathetic tone and its pathophysiologic consequences. The evidence for the association of the coronary risk and borderline and white coat hypertension is given in Table 1 . All subjects with these early forms of hypertension were overweight and had elevated cholesterol, triglyceride, and plasma insulin levels with decreased HDL cholesterol. Subjects with borderline and white coat hypertension also had significant elevation of the heart rate, an epidemiologic index of increased sympathetic tone.

In Tecumseh there are two distinct phenotypes of borderline hypertension; those with the hyperkinetic state and a group with elevated $\mathrm{Li}^{+} / \mathrm{Na}^{+}$countertransport although there is some overlap with some subjects sharing both phenotypes. We know that hyperkinetic borderline hypertension is neurogenic 
Table 1. Metabolic and Hemodynamic Variables in Normotensive, Borderline Hypertensive and White Coat Hypertensive Subjects in the Tecumseh Blood Pressure Study.

\begin{tabular}{|c|c|c|c|}
\hline & Normotensive & Borderline HT & White coat HT \\
\hline Number and Sex $(M / F)$ & $822(402 / 422)$ & $124(93 / 31)$ & $52(38 / 14)$ \\
\hline Age (yr) & $30.6 \pm 0.2$ & $31.4 \pm 0.5$ & $31.5 \pm 0.6$ \\
\hline Weight (kg) & $74.3 \pm 0.5$ & $87.7 \pm 1.3^{* * *}$ & $83.84 \pm 1.7^{* * *}$ \\
\hline Overweight (\%) & $13.6 \pm 0.7$ & $30.1 \pm 1.9^{* * *}$ & $28.7 \pm 2.6^{* * *}$ \\
\hline SBP Clinic & $112.4 \pm 0.3$ & $130.7 \pm 0.9$ ๆ & $127.9 \pm 1.4^{* * *}$ \\
\hline DBP Clinic & $75.4 \pm 0.3$ & $93.9 \pm 0.7$ १ & $92.9 \pm 1.1^{* * *}$ \\
\hline SBP Home & $114.0 \pm 0.9$ & $126.2 \pm 0.9^{\text {I }}$ & $120.6 \pm 1.3^{* *}$ \\
\hline DBP Home & $71.4 \pm 0.4$ & $79.5 \pm 0.7$ ๆ & $75.33 \pm 1.1^{* *}$ \\
\hline Resting HR & $68.7 \pm 0.3$ & $72.8 \pm 0.9^{\text {ๆ }}$ & $77.5 \pm 1.3^{* * *}$ \\
\hline Cholesterol (mg/dl) & $177 \pm 1.2$ & $190.8 \pm 3.5^{\curvearrowleft}$ & $184.9 \pm 4.9$ \\
\hline Triglycerides (mg/dl) & $96.3 \pm 2.7$ & $136.8 \pm 7.2$ ๆ & $133.9 \pm 11.1^{* * *}$ \\
\hline $\mathrm{HDL}(\mathrm{mg} / \mathrm{dl})$ & $43.7 \pm 0.4$ & $40.6 \pm 1.2^{* * *}$ & $38.5 \pm 1.6^{*}$ \\
\hline Glucose (mg/dl) & $91.5 \pm 0.4$ & $95.1 \pm 1.0^{* * *}$ & $93.9 \pm 1.9$ \\
\hline Insulin (munits/ml) & $12.5 \pm 0.4$ & $18.0 \pm 1.6^{\text {ๆ }}$ & $17.1 \pm 1.8^{* *}$ \\
\hline
\end{tabular}

${ }^{\text {ก }} \mathrm{p}<0.0001 ;{ }^{* * *} \mathrm{p}<0.001{ }^{* *} \mathrm{p}<0.01{ }^{*} \mathrm{p}<0.05$ vs. normotensive.

Note that the group with "white coat" hypertension is a subgroup of patients with borderline hypertension.

in origin so it was, therefore, of great interest to analyze whether "pure" hyperkinetic subjects (high cardiac output, fast heart rate but normal $\mathrm{Li}^{+} / \mathrm{Na}^{+}$ countertransport) in Tecumseh also have increased coronary risk. The data is presented in Table 2. Note that these subjects had minimal blood pressure elevation in the office and were normotensive at home. Furthermore, they were not heavy or overweight, but tended to be leaner than their normotensive counterparts. Nevertheless, these "pure" hyperkinetic subjects in Tecumseh did have significantly higher triglycerides, plasma insulin and also, to a lesser degree, cholesterol values. These findings suggest that the insulin/lipid abnormality in the hyperkinetic state is not a consequence of being overweight and that it is closely associated with higher blood pressure readings in a subgroup of subjects who, because they have all the attributes of the hyperkinetic state, are considered to have an enhanced sympathetic cardiovascular tone.

One of the most perplexing and yet unsolved issues in clinical hypertension is the relative lack of efficacy of antihypertensive treatment in controlling the excessive coronary morbidity in patients with hypertension, especially when compared with the substantial benefit on stroke reduction that is derived from similar blood reduction with the same agents (62). This may be an indication that some of the coronary morbidity in hypertension, while associated with the disease, is independent of blood pressure elevation, whereas in cerebrovascular disease it may be that the majority of morbidity is pressure related. It is appealing to suggest that sympathetic overactivity, which we have documented in lean subjects even before they develop any serious or sustained hypertension, is associated with excess coronary risk in its own right, and may play a major role in the pathogenesis of the risk factors themselves (63). A schema for the role of enhanced sym-
Table 2. Anthropometric, Metabolic and Hemodynamic Variables (Adjusted for Sex) in Normotensive and Borderline Hypertensive Hyperkinetic Patients (with Normal $\mathrm{Li}^{+}$. $\mathrm{Na}^{+}$Countertransport) in the Tecumseh Blood Pressure Study

\begin{tabular}{lll}
\hline Variable & Normotensives & $\begin{array}{c}\text { "Pure" } \\
\text { hyperkinetic } \\
\text { borderline }\end{array}$ \\
\hline Number $(\mathrm{M} / \mathrm{F})$ & $787(384 / 403)$ & $24(20 / 4)$ \\
Weight $(\mathrm{kg})$ & 74 & 75 \\
Sum of skinfolds $(\mathrm{mm})$ & 70 & 65 \\
BP office & $113 / 75$ & $135 / 93^{* * *}$ \\
BP home & $115 / 71$ & $117 / 74$ \\
Heart rate $(\mathrm{beats} / \mathrm{min})$ & 74 & $82^{* * *}$ \\
Cardiac index $\left(\mathrm{l} / \mathrm{m}^{2} / \mathrm{min}\right)$ & 2.76 & $3.33^{* * *}$ \\
Cholesterol $(\mathrm{mg} / \mathrm{dl})$ & 175 & 186 \\
Triglycerides $(\mathrm{mg} / \mathrm{dl})$ & 95 & $137^{* *}$ \\
Insulin $(\mu \mathrm{U} / \mathrm{ml})$ & 14.5 & $21.8^{* *}$ \\
\hline
\end{tabular}

${ }^{* *} \mathrm{p}<0.01 ;{ }^{* * *} \mathrm{p}<0.001$.

pathetic and decreased parasympathetic tone in hypertension in the risk of developing coronary heart disease and contributing to higher morbidity in pre-existing coronary heart disease is illustrated in Fig. 2. This Figure also displays how the autonomic abnormality in hypertension may independently contribute to development of atherosclerosis, coronary thrombosis, sudden death and coronary spasm.

\section{Accelerated Atherosclerosis}

The insulin resistance syndrome is a frequent accompaniment of hypertension (58, 64-69). Skeletal muscles are the major site of insulin resistance, as they are in non-insulin dependent diabetes $(70$, 


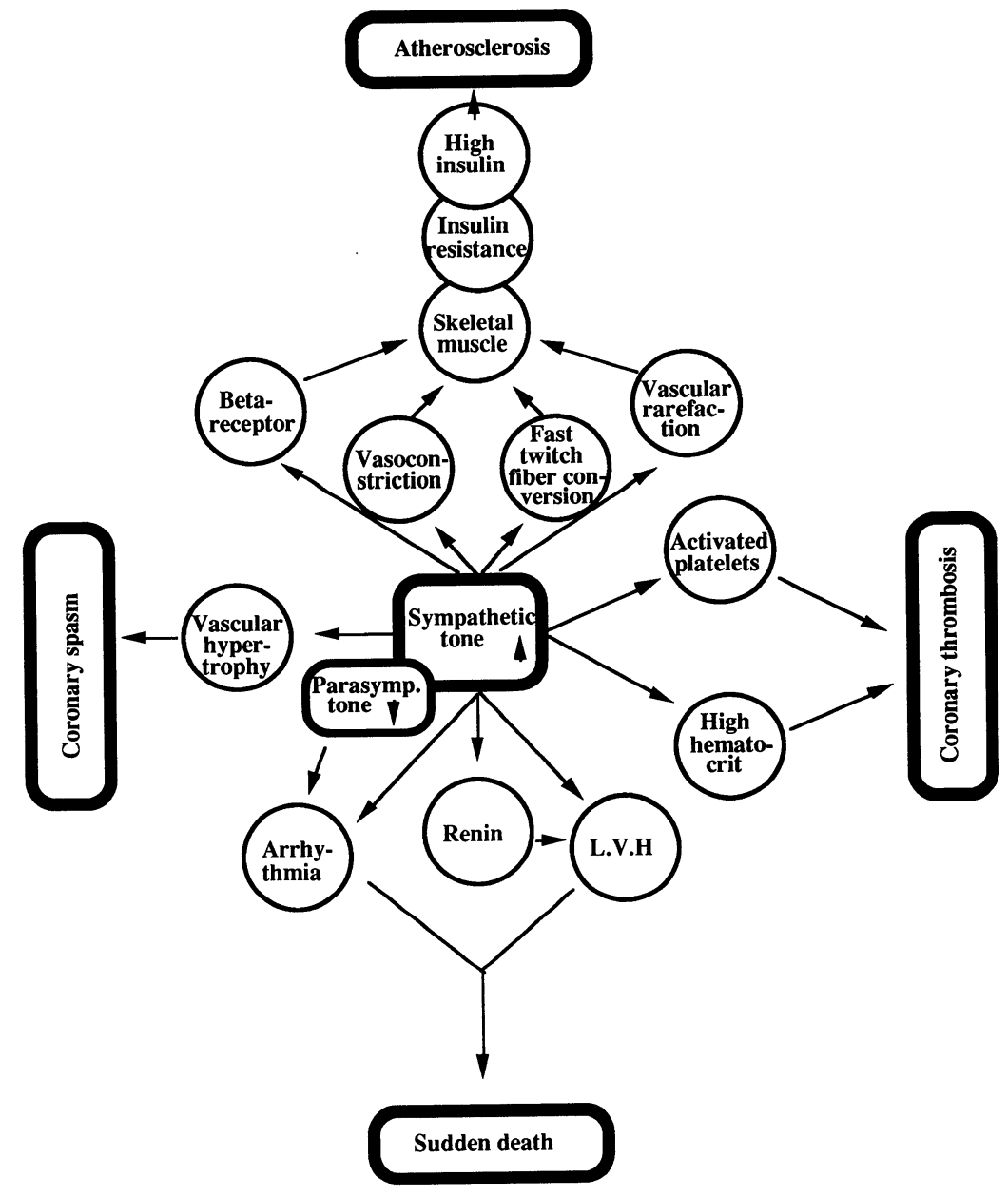

Fig. 2. The effect of changes in autonomic tone on factors influencing cardiac morbidity and mortality.

71), although the underlying biochemical defect may be different (72). It has been shown that high insulin levels are predictive of coronary heart disease (73-76) which may be due to the atherogenetic effects of insulin related to promotion of dyslipidemia (77) and its "trophic" influence on the proliferation of smooth muscle cells $(78,79)$.

Enhanced sympathetic drive in hypertension may be conducive to the development of insulin resistance through a number of mechanisms. It is known that acute $\beta$-adrenergic stimulation with epinephrine causes a receptor-mediated insulin resistance (as the effects can be abolished by propranolol) (80) and that chronic $\beta$-adrenergic stimulation in rats causes a relative increase in the number of fast twitch fibers (81) which are known to be insulin resistant. alpha-adrenergic vasoconstriction is another mechanism by which sympathetic stimulation may cause insulin resistance as we first conceptually proposed $(82,83)$ and then experimentally confirmed when Jamerson (84) showed that reflex activation of sympathetic tone produced vasoconstriction and relative resistance to the actions of insulin. Vascular rarefaction (85), and specifically a decrease in capillary density in skeletal muscle (83), has been observed in human hypertension. This vascular rarefaction (86), due to capillary dropout as a consequence of progressive structural adaptation in chronic hypertension and the ensuing enhancement of vascular responses, may then cause insulin resistance by the same mechanism as vasoconstriction, namely by decreased delivery of glucose to peripheral tissues.

\section{Tendency to Coronary Thrombosis}

Hypertension is known to be associated with increased hematocrit (87-89) and platelet reactivity (90). Both of these factors favor coronary thrombosis and may be a reflection of increased sympathetic tone. It has been shown that infusion of norepinephrine causes an acute decrease of plasma volume in humans (91) through an a-adrenergically mediated increase in postcapillary venous resistance. Similarly, after acute $\beta$-adrenergic blockade, which leaves unopposed $\alpha$-adrenergic tone, there is an immediate decrease of plasma volume and an increase of the hematocrit (92). It stands to reason, therefore, that sympathetically mediated vasoconstriction may be responsible for the observed increase of hematocrit in hypertension. The elevation 
of hematocrit reflects a decrease in plasma volume in hypertension $(93,94)$, and is associated with cardiac hypertrophy (95) and coronary heart disease $(96,97)$, probably by increasing blood viscosity.

In addition to the increased hematocrit, increased platelet reactivity in hypertension may also favor coronary thrombosis. Plasma thromboglobulin, a measure of the platelet turnover, is elevated in hypertension and correlates with increased plasma adrenaline levels in these patients (90). This suggests that excess sympathetic tone may be a factor contributing to the increased risk of myocardial infarction and stroke in the early morning hours.

Tendency to Sudden Death due to Arrhythmia's Left ventricular hypertrophy is a strong risk factor for cardiovascular death, particularly in patients with previous history of coronary heart disease (98). Most of the excessive mortality is due to sudden death; Holter monitoring shows an abundance of arrhythmias in subjects with left ventricular hypertrophy ranging from an increase in ventricular premature beats to recurrent episodes of non-sustained ventricular tachycardia (99). Autonomic imbalance could contribute to producing these arrhythmias and sudden death through two different mechanisms. Sympathetic stimulation may act as a trophic factor favoring hypertrophy of myocardial cells, as it has been shown that stimulation of $\alpha-1$ receptors by norepinephrine induces growth of rat myocytes $(100,101)$. Furthermore, increased sympathetic stimulation of the kidney elicits release of renin, which is characteristically elevated in patients with mild hypertension and high plasma norepinephrine values (36). An increase in plasma renin leads to higher plasma angiotensin II, which is also recognized as a trophic factor $(102,103)$. Thus, norepinephrine and angiotensin are pressure-independent trophic factors which, when increased in patients with hypertension, will further aggravate the pressure-induced tendency towards cardiac hypertrophy. Left ventricular hypertrophy increases the tendency for arrhythmias in its own right but it is likely that the autonomic imbalance which exists in hypertension amplifies the risk of sudden death in such patients.

Sympathetic tone is increased and parasympathetic tone is decreased $(23,104)$ in the hyperkinetic state, which is present in about $30-40 \%$ of all patients with borderline hypertension $(49,105$, 106). As hypertension becomes established, the effect of sympathetic overactivity on the heart rate is less apparent, probably due to a functional downregulation of $\beta$-adrenergic receptors $(53,54)$. However, evidence of decreased parasympathetic tone can still be detected in established hypertension (5). With the development of diastolic dysfunction and left ventricular hypertrophy in the course of hypertension, maintenance of cardiac performance becomes increasingly more dependent on enhanced sympathetic tone. In fact, even in patients with borderline hypertension who have a normal resting cardiac output, an increased reliance of cardiac output on autonomic drive can be found.
When autonomic tone is removed by administration of propranolol and atropine in these individuals, cardiac output falls to significantly subnormal levels (53). It stands to reason that elevated sympathetic tone initially in borderline hypertension and then later in the face of decreasing cardiac function against the constant background of decreased parasympathetic tone in hypertension, increases the propensity to develop arrhythmias (107-110), perhaps by lowering the arrhythmic threshold.

\section{Vascular Hypertrophy and Coronary Spasm}

Three decades ago, Dr. Bjorn Folkow proposed the important concept of "structural reinforcement" of vasoconstriction in hypertension and later provided ample experimental support for its existence (111). In the human body enhanced functional demand eventually leads to structural alterations as an adaptation to the functional need and in order to better support it e.g. cardiac and skeletal muscle hypertrophy in response to chronically elevated blood pressure. Long-standing hypertension leads to hypertrophy of the medial (muscular) layer in resistance arteries. This results in an increase in the wall/lumen ratio so that even when the blood vessel is maximally dilated the thicker arterial wall impinges on the lumen, resulting in an increase in minimal vascular resistance. During vasoconstriction, due to the geometric relationship between the arterial wall and lumen, the wall of the blood vessel encroaches upon the lumen even more, increasing the wall/lumen ratio still further. Since resistance increases exponentially with a smaller radius, the resistance response curve in patients with medial hypertrophy is much steeper than in control subjects. This amplification of the resistance response in hypertension has been well documented $(4,56)$. We have also shown that increased vascular resistance in hypertension is characteristic of patients with higher plasma norepinephrine values (56). If the vessel wall is hypertrophic and the vasoconstriction substantial, the lumen of the vessel can completely close (85). When structural reinforcement involves the coronary microvascular resistance vessels they become hyperresponsive to all vasoconstrictive influences, including emotional stress (112, $113)$. In this setting, these type of stimuli may precipitate myocardial ischemia by producing microvascular spasm, even in the absence of left ventricular hypertrophy and epicardial coronary artery disease.

This conceptual association between the autonomic nervous system, hypertension and cardiac events is summarized in Figure 2. Sympathetic overactivity in hypertension may independently lead to insulin resistance and hyperlipidemia which, in turn, favors early development of atherosclerosis. Similarly, enhanced sympathetic tone causes a decrease of plasma volume and activates platelets, a combination that favors coronary thrombosis. The other two cardiac complications, predisposition to arrhythmia and vasospasm, are largely a consequence of the "structural reinforcement" induced by hypertension effecting the heart and its vasculature. 


\section{The "Purpose" of the Sympathetic Overactivity in Hypertension}

As shown above, sympathetic overactivity may explain the observed complex of blood pressure elevation, risk of premature coronary heart disease and increased coronary morbidity in hypertension. It is hard to accept that these complex relationships exist purely on the basis of chance. If this is not the case, what could be the reason for such a multifaceted interrelationship?

We wish to propose the hypothesis that enhanced sympathetic activity and its consequences, namely insulin resistance and tendency toward hypercoagulability, are remnants of the "defense reaction". In postulating this we are reiterating the principle voiced by Dr. James Neel when he put forward the "thrifty gene" hypothesis for diabetes (114). According to this hypothesis, in the course of evolution a trait which may have offered a survival advantage early in human development, may become detrimental with the advent of extended longevity in modern society. The defense reaction is an emotional-physiologic complex, which originates from specific areas in the paleocortex, and whose circulatory characteristics are an increase in blood pressure and cardiac output. These circulatory changes enable the organism to react appropriately to threat by responding more efficiently during the anticipated effort of "fight or flight" $(55,115)$. The hemodynamic profile in patients with hyperkinetic borderline hypertension is exactly what is seen in the defense reaction, namely an elevated blood pressure, a high cardiac output and increased blood flow to skeletal muscle $(3,116$ 118).

Whereas the circulatory adjustment during the defense reaction is generally accepted as a meaningful preparatory response, there may be other aspects to the defense reaction that are equally useful but less well investigated. The circulatory response of high cardiac output and elevated blood pressure was, in the old literature, called "adrenaline-like" as it closely resembled the response to adrenaline infusions. It was recognized that infusion of adrenaline suppressed insulin release from the pancreas (119), before Diebert and DeFronzo showed that infusion of epinephrine caused acute insulin resistance $(80)$ which appeared to be mediated by $\beta$-adrenergic receptors, as it was reversible with propranolol. As an adjunct to the circulatory response, suppressed insulin release and insulin resistance during the defense reaction are also likely to be functionally useful. Decreased insulin release will raise the blood glucose while acute insulin resistance will prevent skeletal muscles from utilizing it all as their metabolic needs increase. This ensures the brain will be adequately supplied with glucose, on which it is critically dependent, and which can be utilized even in the absence of insulin. Thus, during the defense reaction, there is an "economy of fuel utilization" so that adequate fuel supplies are maintained to the two organs most important under the circumstances, the skeletal mus- cles and the brain, to ensure optimal function. Sympathetic activation during the defense reaction may also increase the hematocrit and activate platelets, which from the vantage point of the defense reaction, appears to be a fitting response in anticipation of possible injuries.

It is conceivable that individuals with a more pronounced defense reaction were better able to cope with hardship and thus improved their chances of survival. This survival advantage may have resulted in the selective passage of genes which may now predominately reside in a significant proportion of present day hypertensive subjects. The relative absence of immediate life-threatening danger in contemporary society makes the benefits of these genes obsolete and the longer life expectancy of modern times thus exposes the disadvantages of these inherited traits. In the era of shorter life expectancy the excessive sympathetic activity allowed by these genes may have been useful but with the increasing longevity of modern times it may contribute to a faster deterioration of overall cardiovascular function.

\section{References}

1. Geisbock W: Die bedeutung der blutdruckmessung fur die praxis. Dtsch Arch Klin Med 1905; 83: 363-374.

2. Pickering GW: The peripheral resistance in persistent arterial hypertension. Clin Sci 1936; 2: 209.

3. Conway $\mathbf{J}:$ A vascular abnormality in hypertension: a study of blood flow in the forearm. Circulation 1963; 27: 520-529.

4. Sivertsson R: The hemodynamic importance of structural vascular changes in essential hypertension. Acta Physiol Scand 1970; 79 (suppl 343): 3-56.

5. Korner PI, Shaw J, Uther JB., West MJ, McRitchie RJ, Richards JG: Autonomic and non-autonomic circulatory components in essential hypertension in man. Circulation 1973; 48: 107-117.

6. Julius S, Egan B: Hemodynamics of hypertension, in Zanchetti A, Tarazi RC (eds): Handbook of Hypertension. vol. 7: pathophysiology of hypertension-cardiovascular aspects. Amsterdam, Elsevier, 1986, pp153-178.

7. Goldstein DS: Plasma norepinephrine in essential hypertension: a study of the studies. Hypertension 1981; 3: 48-52.

8. Goldstein DS: Plasma catecholamines and essential hypertension: an analytical review. Hypertension 1983; 5: 86-99.

9. Ferrario CM, McCubbin JW, Page IH: Hemodynamic characteristics of chronic experimental neurogenic hypertension in unanesthetized dogs. Circ Res 1969; 29: 911-922.

10. Folkow B, Rubinstein EH: Cardiovascular effects of acute and chronic stimulation of the hypothalamic defense area in the rat. Acta Physiol Scand 1966; 68: 48-57.

11. Liard JF, Tarazi RC, Ferrario CM, Manger WM: Hemodynamic and humoral characteristics of hypertension induced by prolonged stellate ganglion stimulation in conscious dogs. Circ Res 1975; 36: 455-465.

12. Rothlin E, Cerletti A, Emmenegger H: Experimental psycho-neurogenoc hypertension and its treatment with hydrogenated ergot alkalois (hydergine). Acta 
Med Scand 1956; 154(suppl 312): 27-35.

13. Herd JA., Morse WH, Kelleher RT, Jones LG: Arterial hypertension in the squirrel monkey during behavioral experiments. Am J Physiol 1969; 217: 24-29.

14. Guyton AC, Coleman TG: Quantitative analysis of the pathophysiology of hypertension. Circ Res 1969; 24-25 (suppl I): 1-19.

15. Eich RH, Peters RJ, Cuddy RP, Smulyan H, Lyons $\mathrm{RH}$ : The hemodynamics in labile hypertension. $A m$ Heart J 1962; 63: 188-195.

16. Sannerstedt R, Julius S, Conway J: Hemodynamic response to tilt and beta-adrenergic blockade in young patients with borderline hypertension. Circulation 1970; 42: 1057-1064.

17. Lund-Johansen P: Hemodynamics in early essential hypertension. Acta Med Scand 1967; 482 (suppl): 1-105.

18. Julius $\mathrm{S}$, Conway $\mathrm{J}$ : Hemodynamic studies in patients with borderline blood pressure elevation. Circulation 1968; 38: 282-288.

19. Frohlich ED., Kozul VJ., Tarazi RC, Dustan HP: Physiological comparison of labile and essential hypertension. Circ Res 1970; 26 (suppl I): 55-69.

20. Sannerstedt, R: Hemodynamic response to exercise in patients with arterial hypertension. Acta Med Scand 1966; 458 (suppl): 1-83.

21. Julius S, Pascual A, Sannerstedt R, Mitchell, C: Relationship between cardiac output and peripheral resistance in borderline hypertension. Circulation 1971; 43: $382-390$.

22. Julius S, Ibsen H, Colfer HT: Hemodynamic and pharmacologic correlates of plasma norepinephrine in hypertension, in Ziegler MG, Lake CR (eds); Norepinephrine. vol. 2: frontiers of clinical neuroscience. Baltimore, Williams \& Wilkins, 1984, pp401-409.

23. Julius S, Pascual AV, London R: Role of parasympathetic inhibition in the hyperkinetic type of borderline hypertension. Circulation 1971; 44: 413-418.

24. Frohlich ED, Tarazi RC, Dustan HP: Hyperdynamic beta-adrenergic circulatory state: increased beta-receptor responsiveness. Arch Intern Med 1969; 123: 1-7.

25. Takeshita A, Tanaka S, Kuroiwa A, Nakamura M: Reduced baroreceptor sensitivity in borderline hypertension. Circulation 1975; 51: 738-742.

26. Eckberg DL; Carotid baroreflex function in young men with borderline blood pressure elevation. Circulation 1979; 59: 632-636.

27. Volpe M, Trimarco B, Ricciardelli B, et al: The autonomic nervous tone abnormalities in the genesis of the impaired baroreflex responsiveness in borderline hypertensive subjects. Clin Sci 1982; 62: 581-588.

28. Ookuwa H, Takata S, Ogawa J, Iwase N, Ikeda T, Hattori N: Abnormal cardiopulmonary baroreflexes in normotensive young subjects with a family history of essential hypertension. J Clin Hypertens 1987; 3: 596-604.

29. Julius S: Borderline hypertension: clinical and pathophysiologic significance, in von $P$ Frick $H$, von Harnack GA, Martinini GA, Prader A, Schoen R, Wolff HP: Advances in Internal Medicine and Pediatrics (vol. 41). Heidelberg, Springer-Verlag, 1978, pp52-84.

30. Anderson EA, Sinkey CA, Lawton WJ, Mark AL: Elevated sympathetic nerve activity in borderline hypertensive humans: evidence from direct intraneural recordings. Hypertension 1989; 14: 177-183.

31. Yamada Y, Miyajima E, Tochikubo O, Matsukawa $\mathrm{T}$, Ishii M: Age-related changes in muscle sympathe- tic nerve activity in essential hypertension. Hypertension 1989; 13, 6 Part 2: 870-877.

32. Yamada Y, Miyajima E, Tochikubo O, et al: Impaired baroreflex changes in muscle sympathetic nerve activity in adolescents who have a family history of essential hypertension. J Hypertens 1988; 6 (suppl 4): S525-S528.

33. Matsukawa $\mathrm{T}$, Gotoh E, Uneda $\mathrm{S}$, et al: Augmented sympathetic nerve activity in response to stressors in young borderline men. Acta Physiol Scand 1991; 141: 157-165.

34. Floras JS, Hara K: Sympathoneural and haemodynamic characteristics of young subjects with mild essential hypertension. J Hypertens 1993; 11: 647-655.

35. Guzzetti S, Piccaluga E, Casati R, et al: Sympathetic predominance in essential hypertension: a study employing spectral analysis of heart rate variability. $J$ Hypertens 1988; 6: 711-717.

36. Esler M, Julius S, Zweifler A, et al: Mild high-renin essential hypertension: nurogenic human hypertension? N Engl J Med 1977; 296: 405-411.

37. Esler M, Lambert G, Jennings G: Regional norepinephrine turnover in human hypertension. Clin Exp Hypertens 1989; A11 (suppl 1): 75-89.

38. Levy RL, White PD, Stroud WD, Hillman CC: Transient tachycardia: prognostic significance alone and in association with transient hypertension. JAMA 1945; 129: 585-588.

39. Paffenbarger RS Jr, Thorne MC, Wing AL: Chronic disease in former college students: VIII. characteristics in youth predisposing to hypertension in later years. Am J Epidemiol 1968; 88: 25-32.

40. Stamler J, Berkson DM, Dyer A, et al: Relationship of multiple variables to blood pressure-Findings from four Chicago epidemiologic studies, in Paul O (ed): Epidemiology and Control of Hypertension. Miami, Symposia Specialists, 1975, pp307-352.

41. Eich RH, Cuddy RP, Smulyan H, Lyons RH: Hemodynamics in labile hypertension: a follow-up study. Circulation 1966; 34: 299-307.

42. Safar ME, Weiss YA, Levenson JA, London GM, Milliez PL: Hemodynamic study of 85 patients with borderline hypertension. Am J Cardiol 1973; 31: 315-319.

43. Julius S, Quadir H, Gajendragadkar, S: Hyperkinetic state: a precursor of hypertension? a longitudinal study of borderline hypertension, in Gross F, Strasser $T$ (eds): Mild Hypertension: Natural History and Management, London, Pittman Medical Publishing Co. Ltd., 1979, 116-126.

44. Lund-Johansen P: Haemodynamic observations in mild hypertension, in Gross F, Strasser T (eds): Mild Hypertension: Natural History and Management, London, Pittman Medical Publishing Co. 1979, $102-115$

45. Lund-Johansen, P: Central haemodynamics in essential hypertension at rest and during exercise: a 20year follow-up study . J Hypertens 1989; 7 (Suppl 6): S52-S55.

46. Julius S, Schork MA: Borderline hypertension-a critical review. J Chronic Dis 1971; 23: 723-754.

47. Australian National Blood Pressure Study, The Australian therapeutic trial in mild hypertension. Lancet 1980; 1: 1261-1267.

48. Schork NJ, Schork MA: Skewness and mixtures of normal distributions. Commun Stat 1988; 17: 3951-3969.

49. Julius S, Krause L, Schork N, et al: Hyperkinetic borderline hypertension in Tecumseh, Michigan. $J$ Hypertens 1991; 9: 77-84.

50. Kawano Y, Fukiyama K, Takeya T, Abe I, Omae T: 
Elevated plasma catecholamines without alteration in cardiovascular responsiveness in young men with borderline hypertension. Am Heart J 1982; 104: 1351-1356.

51. Aoi W, Kuramochi M, Hashiba K: Neurohumoral factors in borderline hypertension. Jpn Circ J 1983; 47: 258-267.

52. Kawano Y, Fukiyama K, Takeya Y, Abe I, Kawasaki T, Omae T: Augmented sympathetic nervous function in young subjects with borderline hypertension. Jpn Circ J 1982; 46: 483-485.

53. Julius S, Randall OS, Esler MD, Kashima T, Ellis $\mathrm{CN}$, Bennett $\mathrm{J}$ : Altered cardiac responsiveness and regulation in the normal cardiac output type of borderline hypertension. Circ Res 1975; 36-37 (suppl I): I-199-I-207.

54. Trimarco B, Volpe M, Ricciardelli B, et al: Studies of the mechanisms underlying impairment of betaadrenoceptor-mediated effects in human hypertension. Hypertension 1983; 5: 584-590.

55. Folkow B: Physiological aspects of primary hypertension. Physiol Rev 1982; 62: 347-503.

56. Egan B, Panis R, Hinderliter A, Schork N, Julius S: Mechanism of increased alpha-adrenergic vasoconstriction in human essential hypertension. J Clin Invest 1987 ; 80: $812-817$.

57. Julius S: Editorial review: the blood pressure seeking properties of the central nervous system. J Hypertens 1988; 6: 177-185.

58. Ferrannini E, Buzzigoli G, Bonadonna R, et al: Insulin resistance in essential hypertension. $N$ Engl $J$ Med 1987; 317: 350-357.

59. Williams RR, Hunt SC, Hopkins PN, et al: Familial dyslipidemic hypertension. JAMA 1988; 259: 3579-3586.

60. Kaplan NM: The deadly quartet. Upper body obesity, glucose intolerance, hypertriglyceridemia and hypertension. Arch Intern Med 1989; 149: 1514-1520.

61. Julius S, Mejia, A, Jones K, et al: "White coat" versus "sustained" borderline hypertension in Tecumseh, Michigan. Hypertension 1990; 16: 617-623.

62. Collins R, Peto R, MacMahon S, et al: Blood pressure, stroke, and coronary heart disease. Part 2, short-term reduction in blood pressure: overview of randomised drug trials in their epidemiological context. Lancet. $1990 ;$ 335: 827-838.

63. Julius S, Jamerson K: Sympathetics, insulin resistance and coronary risk in hypertension: the 'chickenand-egg' question. J Hypertens 1994; 12: 495-502.

64. Modan M, Halkin H, Almog S, et al: Hyperinsulinemia. A link between hypertension obesity and glucose intolerance. J Clin Invest 1985; 75: 809-817.

65. Reaven GM: Insulin resistance and compensatory hyperinsulinemia: role in hypertension, dyslipidemia, and coronary heart disease. Am Heart J 1991; 121: 1283-1288.

66. Fujita N, Baba T, Tomiyama T, Kodama T, Kako N: Hyperinsulinaemia and blood pressure in patients with insulinoma. Br Med J 1992; 304: 1157.

67. Kageyama S, Yamamoto J, Mimura A, et al: Comparison of effects of nicardipine and trichlormethiazide on insulin sensitivity in hypertensive patients. Am J Hypertens 1994; 7: 474-477.

68. Saito I, Nishino M, Kawabe, $\mathrm{H}$, et al: Leisure time physical activity and insulin resistance in young obese students with hyperstension. Am J Hypertens 1992; 5: 915-918.

69. Suzuki M, Hirose J, Asakura Y, et al: Insulin insensitivity in nonobese, nondiabetic essential hypertension and its improvement by an alpha 1-blocker (bunazosin). Am J Hypertens 1992; 5: 869-874.
70. Natali A, Santoro D, Palombo C, Cerri M, Ghione $S$, Ferrannini E: Impaired insulin action on skeletal muscle metabolism in essential hypertension. Hypertension 1991; 17: 170-178.

71. DeFronzo RA, Gunnarsson R, Bjorkman O, Olsson $M$, Wahren $\mathrm{J}$ : Effects of insulin on peripheral and splanchnic glucose metabolism in noninsulin-dependent (type II) diabetes mellitus. J Clin Invest 1985; 76: $149-155$.

72. Haring HU: The insulin receptor: signalling mechanism and contribution to the pathogenesis of insulin resistance. Diabetologia 1991; 34: 848-861.

73. Welborn TA, Wearne K: Coronary heart disease incidence and cardiovascular mortality in Busselton with reference to glucose and insulin concentrations. Diabetes Care 1979; 2: 154-160.

74. Ducimetiere P, Eschwege E, Papoz L, Richard JL, Claude JR, Rosselin G: Relationship of plasma insulin levels to the incidence of myocardial infarction and coronary heart disease mortality in a middleaged population. Diabetologia 1980; 19: 205-210.

75. Pyorala K: Relationship of glucose tolerance and plasma insulin to the incidence of coronary heart disease: results from two population studies in Finland. Diabetes Care 1979; 2: 131-141.

76. Pyorala K, Savolainen E, Kaukola S, Haapakoski, J: Plasma insulin as a coronary heart disease risk factor: relationship to other risk factors and predictive value during $91 / 2$ year follow-up of the Helsinki Policemen Study population. Acta Med Scand Suppl 1985; 701: 38-52.

77. DeFronzo RA, Ferrannini E: Insulin resistance: a multifaceted syndrome responsible for NIDDM, obesity, hypertension, dyslipidemia, and atherosclerotic cardiovascular disease. Diabetes Care 1991; 14: 173-194.

78. King GL, Goodman D, Buzney S, Moses A, Kahn $\mathrm{CR}$ : Receptors and growth promoting effects of insulin and insulin like growth factors on cells from bovine retinal capillaries and aorta. J Clin Invest 1985; 75: 1028-1036.

79. Stout RW, Bierman EL, Ross R: Effect of insulin on the proliferation of cultured primate arterial smooth muscle cells. Circ Res 1975; 36: 319-327.

80. Deibert DC, DeFronzo RA: Epinephrine-induced insulin resistance in man. J Clin Invest 1980; 65: 717-721.

81. Zeman RJ, Ludemann R, Easton TG, Etlinger JD: Slow to fast alterations in skeletal muscle fibers caused by clenbuterol, a beta-2-receptor agonist. Am J Physiol 1988; 254: E726-E732.

82. Julius S, Gudbrandsson T, Jamerson K, Shahab ST, Andersson O: Hypothesis: the hemodynamic link between insulin resistance and hypertension. J Hypertens 1991; 9: 983-986.

83. Julius S, Gudbrandsson T, Jamerson K, Andersson $O$ : The interconnection between sympathetics, microcirculation, and insulin resistance in hypertension. Blood Pressure 1992; 1: 9-19.

84. Jamerson KA, Julius S, Gudbrandsson T, Andersson $\mathrm{O}$, Brant DO: Reflex sympathetic activation induces acute insulin resistance in the human forearm. Hypertension 1993; 21: 618-623.

85. Sullivan JM, Prewitt RL, Josephs JA. Attenuation of the microcirculation in young patients with high-output borderline hypertension. Hypertension 1983; 5: 844-851.

86. Greene AS, Tonellato PJ, Lui J, Lombard JH, Cowley AW Jr: Microvascular rarefaction and tissue vascular resistance in hypertension. Am J Physiol 1989; 256: H126-H131. 
87. Tibblin G, Bergentz S-E, Bjure J, Wilhelmsen L: Hematocrit, plasma protein, plasma volume, and viscosity in early hypertensive disease. Am Heart $J$ 1966; 72: 165-176.

88. Cirillo M, Laurenzi M, Trevisan M, Stamler J: Hematocrit, blood pressure, and hypertension: the gubbio population study. Hypertension 1992; 20: 319-326.

89. Smith WCS, Lowe GDO, Lee AJ, Tunstall-Pedoe $\mathbf{H}$ : Rheological determinants of blood pressure in a Scottish adult population. J Hypertens 1992; 10: 467-472.

90. Kjeldsen SE, Gjesdal K, Eide I, et al: Increased beta-thromboglobulin in essential hypertension: interactions between arterial plasma adrenaline, platelet function and blood lipids. Acta Med Scand 1983; 213: 369-373.

91. Cohn JN: Relationship of plasma volume changes to resistance and capacitance vessel effects of sympathomimetic amines and angiotensin in man. Clin Sci 1966; 30: 267-278.

92. Julius S, Pascual AV, Abbrecht P, London R: Effect of beta-adrenergic blockade on plasma volume in human subjects. Proc Soc Exp Biol Med 1972; 140: 982-985.

93. Julius S, Pascual A, Reilly K, London R: Abnormalities of plasma volume in borderline hypertension. Arch Intern Med 1971; 127: 116-119.

94. Tarazi RC, Frohlich ED, Dustan HP: Plasma volume in men with essential hypertension. $N$ Engl $\mathrm{J}$ Med 1968; 278: 762-765.

95. Devereux RB, Drayer JIM, Chien S, et al: Whole blood viscosity as a determinant of cardiac hypertrophy in systemic hypertension. Am J Cardiol 1984; 54: 592-595.

96. Sorlie PD, Garcia-Palmieri MR, Costas R Jr, Havlik RJ: Hematocrit and risk of coronary heart disease: the Puerto Rico Heart Health Program. Am Heart J 1981; 101: 456-461.

97. Salonen JT, Nyyssonen K, Korpela H, Tuomilehto J, Seppanen R, Salonen R: High stored iron levels are associated with excess risk of myocardial infarction in eastern Finnish men. Circulation 1992; 86: 803-811.

98. Kannel WB, Gordon T, Castelli WP, Margolis JR: Electrocardiographic left ventricular hypertrophy and risk of coronary heart disease: the Framingham study. Ann Intern Med 1970; 72: 813-822.

99. Levy D, Garrison RJ, Savage DD, Kannel WB, Castelli WP: Prognostic implications of echocardiographically determined left ventricular mass in the Framingham heart study. $N$ Engl J Med 1990; 322: 1561-1566.

100. Simpson P: Norepinephrine-stimulated hypertrophy of cultured rat myocardial cells is an $\alpha_{1}$-adrenergic response. J Clin Invest 1983; 72: 732-738.

101. Simpson P: Stimulation of hypertrophy of cultured neonatal rat heart cells through an $\alpha_{1}$-adrenergic receptor and induction of beating through an $\alpha_{1}$ - and $\beta_{1}$-adrenergic receptor interaction. Circ Res 1985; 56: 884-894.

102. Simon G, Altman S: Subpressor angiotensin II is a bifunctional growth factor of vascular muscle in rats. J Hypertens 1992; 10: 1165-1171.

103. Schelling P, Fischer H, Gantlen D: Angiotensin and cell growth: a link to cardiac hypertrophy? J Hypertens 1991; 9: 3-15.

104. Bohm R, van Baak M, van Hooff M, Moy J, Rahn KH: Salivary flow in borderline hypertension. Klin Wochenschr 1985; 63 (suppl 3): 154-156.

105. Schork NJ, Weder AB, Schork MA, Bassett DR, Julius S: Disease entities, mixed multi-normal distributions, and the role of the hyperkinetic state in the pathogenesis of hypertension. Stat Med 1990; 9: 301-314.

106. Julius S, Schork N, Schork A: Sympathetic hyperactivity in early stages of hypertension: the Ann Arbor data set. J Cardiovasc Pharmacol 1988; 12 (suppl 3): S121-S129.

107. Berenson GS, Voors AW, Webber LS, Dalferes ER $\mathrm{Jr}$, Harsha DW: Racial differences of parameters associated with blood pressure levels in children: the Bogalusa heart study. Metabolism 1979; 28: 1218-1228.

108. Kannel WB, Kannel C, Paffenbarger RS Jr, Cupples LA: Heart rate and cardiovascular mortality: the Framingham study. Am Heart J 1987; 113: 1489-1494.

109. Gillman MW, Kannel WB, Belanger A, D'Agostino RB: Influence of heart rate on mortality among persons with hypertension: the Framingham study. Am Heart J 1993; 125: 1148-1154.

110. Perski A, Olsson G, Landou C, de Faire U, Theorell $\mathrm{T}$, Hamsten A: Minimum heart rate and coronary atherosclerosis: independent relations to global severity and rate of progression of angiographic lesions in men with myocardial infarction at a young age. $A m$ Heart J 1992; 123: 609-616.

111. Folkow, B, Grumby G, Thulesius O: Adaptive structural changes of the vascular wall in hypertension and their relationship to control of the peripheral resistance. Acta Physiol Scand 1958; 44: 255.

112. Brush JE, Cannon RO Schenke WH, et al: Angina due to coronary microvascular disease in hypertensive patients without left ventricular hypertrophy. $N$ Engl J Med 1988; 319 (20): 1302-1307.

113. Vogt M, Motz W, Schwartzkopff B, Strauer B: Coronary microangiopathy and cardiac hypertrophy. Eur Heart J 1990; 11 (suppl B): 133-138.

114. Neel JV: Diabetes mellitus: a "thrifty" genotype rendered detrimental by "progress"? Am J Hum Genet 1962; 14: 353-362.

115. Folkow B, Lisander B, Tuttle RS, Wing SC: Changes in cardiac output upon stimulation of the hypothalamic defense area and the medullary depressor area in the cat. Acta Physiol Scand 1968; 72: 220-233.

116. Amery A, Bossaert H, Verstraete M: Muscle blood flow in normal and hypertensive subjects: influence of age, exercise, and body position. Am Heart $J$ 1969; 78: $211-216$.

117. Conway J: Hemodynamic aspects of essential hypertension in humans. Physiol Rev 1984; 64: 617-660.

118. Anderson EA. Mahoney LT, Lauer RM, Clarke WR: Enhanced foream blood flow during mental stress in children of hypertensive parents. Hypertension 1987; 10: 544-549.

119. Porte DJr: A receptor mechanism for the inhibition of insulin release by epinephrine in man. J Clin Invest 1967; 46: 86-94. 